\title{
Effects of Perches on Behavior, Heart Rate, Body Temperature and Locomotor Activity of Caged Hens
}

\author{
Kanji Matsui, Ashraf M. Khalil and Ken-ichi Takeda \\ Faculty of Agriculture, Shinshu University, \\ 8304 Minamiminowa-mura, Nagano 399-4598, Japan
}

\begin{abstract}
This study was carried out to investigate the behavior and physiological conditions of hens housed in cages with or without perches. The physiological parameters investigated were heart rate (HR), body temperature (BT) and locomotor activity (LA) using a radiotelemetry system. Six White Leghorn hens (90-weeks-old) were used after transmitters implantation. Following the preconditioning period for at least 10 days, the behavioral and physiological data were recorded for 2 consecutive days, which were the data in the control cages without perches (C). After that, the same hens were exposed to the following types of cages : conventional cages with perches available all day (P24), followed by conventional cages with perches from 19.00 to 08.00 hours (P13), and finally housed in conventional cages with perches from 19.00 to 04.00 hours (P9). The interval between each trial was a 10 days to habituate the hens with their new environment. Immediately following this, the behavioral and physiological data were recorded for 2 consecutive days for each trial. The only significant behavioral difference was found in the time consumed in resting, which increased significantly in P24 cages than in C and P 9 cages $(\mathrm{P}<0.05)$. Our physiological data during the light period indicate that the hens in $\mathrm{P} 24, \mathrm{P} 13$ and $\mathrm{P} 9$ cages had a significantly higher heart rate than in $\mathrm{C}$ cages $(\mathrm{P}<0.01)$. On the other hand, hens in P24 cages had a significantly lower BT than in C, P13, and $\mathrm{P} 9$ cages $(\mathrm{P}<0.01)$, however, hens in $\mathrm{P} 24$ cages had a significantly higher LA than in $\mathrm{C}$, $\mathrm{P} 13$ and $\mathrm{P} 9$ cages $(\mathrm{P}<0.01)$. Moreover, during the dark period, hens in $\mathrm{P} 24$ cages had a significantly lower HR, BT and LA than all the other treatment $(P<0.01)$. These results suggest that the use of cages with perches might be important for the hens' welfare than those without perches.
\end{abstract}

Key words : body temperature, heart rate, hens, locomotor activity, perch

\section{Introduction}

There is increased concern for the welfare of confined animals such as birds confined in battery cages. Criticisms have been leveled at the industry for not allowing these birds to meet their basic behavioral needs. Generally, one of the most striking features of the battery cage as an environment is that hens are kept permanently on a sloping wire floor. This constrains behavior and may also have other features of the cage environment such as lack of facilities, does not allow them to perform many

Received : August 25, 2003, Accepted : January 20, 2004

Correspondence : Kanji Matsui, Faculty of Agriculture, Shinshu University, 8304 Minamiminowa-mura,

Nagano 399-4598, Japan

E-mail : kmatsui@gipmc.shinshu-u.ac.jp

Tel \& Fax : +81-265-77-1426 
natural behaviors, and may have physical effects on the hens. Physical effects may include damage to the feet from the wire : by the end of a laying year hens' feet often show excessive hyperkeratosis and fissuring (Duncan et al., 1992). So, it is believed that an environmental enrichment of the cages such as the provision of perch would benefit the hens in terms of well-being, which is more broadly defined as animal welfare. Therefore, it is widely accepted that perches in laying cages are advantageous for the welfare of hens, providing them with an appropriate place to roost and eliminating the need to spend the entire laying year standing on a sloping floor made of thin wire (Braastad, 1990 ; Tauson, 1984 ; Hughes and Appleby, 1989 ; Duncan et al., 1992). A number of reports have suggested that the provision of perches may improve the productivity, welfare, and physical condition of hens housed in cages. For example, there was a slight trend toward greater weight gain and feed conversion efficiency when hens housed in pens were provided with perches (Hughes and Elson, 1977). Other researchers reported that provision of perches might reduce discomfort or frustration, provide more comfortable environment and improve well-being (Webster and Hurnik, 1990 ; Tanaka et al., 1993). Moreover, perches usually reduce plumage damage (Brasstad, 1990 ; Robertson et al., 1989), and they may also reduce damage to the soles of the feet (Roberston et al., 1989), increase the strength of leg bones (Hughes and Appleby, 1989) or skeletal bone structure (Wilson et al., 1993), and may indeed improve performance under high stocking density compared to conventional cages without perches (Hughes and Elson, 1977). However, the only consistent disadvantage to production has been an increase in the number of cracked eggs in cages with perches (Appleby, 1995 ; Dorminey and Arscott, 1971 ; Duncan et al., 1992 ; Ruzler and Quisenberry, 1970). Regardless of these disadvantages, the conventional caging of laying hens is being banned, and certain environmental enrichment devices such as perches must be provided to all chickens (Tauson, 1998). On the other hand, there have been no reports about changes in physiological variables (heart rate, body temperature, and locomotor activity) when using perches in caged hens.

The object of the present experiment, therefore, was to use behavioral and physiological data to develop an integrated assessment of the response of hens housed in cages with or without perches.

\section{Materials and Methods}

\section{Animals}

Six White Leghorn hens 90-weeks-old with weighing1500-2000 g, were used. These hens were reared in floor pen up to 18 weeks-old. After that, they housed individually in battery cages. In the present, the hens transferred to the experimental room and they were individually caged under the constant environmental conditions : ambient temperature, $20 \pm 2{ }^{\circ} \mathrm{C}$; relative humidity, $40 \pm 5 \%$. The cages were made of wire mesh and measured $41 \mathrm{~cm}$ (rear height), $43 \mathrm{~cm}$ (front height) $\times 26 \mathrm{~cm}$ (width) $\times 40$ $\mathrm{cm}$ (depth). The hen house in which the cages were located was artificially illuminated during a photoperiod (lights-on) from 04.00 to 19.00 hours, 120 lux at cage level provided by a 40 -watt cool-white fluorescent tube. Food and water were available $a d$ 
libitum at all times, and a caretaker entered the room once a day between 08.00 and 09.00 hours. The perches were made of soft wood and were rectangular $(30 \times 40 \mathrm{~mm})$ with rounded edges. They were mounted $200 \mathrm{~mm}$ from the rear wall and $80 \mathrm{~mm}$ above the cage floor (measured from the center of the perch) by two eyescrews on each end which were fastened to the wired side walls. All experimental procedures for the use and the care of animals in the present study were approved by the Animal Care Committee of the Faculty of Agriculture of Shinshu University.

Heart rate (HR), body temperature (BT), and locomotor activity (LA)

Heart rate (HR), body temperature (BT) and locomotor activity (LA) were measured by a radiotelemetry system. The hens were first anesthetized by an intramuscular injection of Ketamine $(100 \mathrm{mg} / \mathrm{kg}$ ) and an intravenous injection of Nembutal $(0.5 \mathrm{mg} / \mathrm{kg})$ under sterile conditions. A telemetric transmitter (TA11CTA-F 40, Data Science, St. Paul, MN, USA) was implanted intraperitoneally. The electrodes for electrocardiogram (ECG) were fixed subcutaneously to the ventral and dorsal sides of the sternum to minimize contact with muscular tissue and to obtain high-quality ECG recordings, as described by Korte et al. (1999). Frequency-modulated ECG, BT and LA signals were received by a signal receptor board (RPC-1, Data Science, St. Paul, MN, USA) and recorded by an ECG processor (Softron, Tokyo, Japan). LA was telemetrically monitored by measuring the movements of the hens in relation to the receiver which gives a signal to the horizontal movement of the hen. HR was calculated from ECG recordings. Samples (10s) of HR and BT were stored every 1 min, and LA was counted continuously and stored at 5 min intervals.

\section{Behavioral observations and experimental design}

The behavior patterns of each hen were recorded on videotape for 2 whole days using an infrared video camera (Sony CCD-TR 180, Tokyo, Japan) and a video recorder (Panasonic NV-N20, Tokyo, Japan) set at one-third normal recording speed. Videotapes were replayed for the behavioral analysis at normal speed in the laboratory. The hens were kept in the constant environmental conditions for at least 10 days after transmitters implantation. Following this preconditioning period, the normal behavioral and physiological data were recorded for 2 consecutive days, which were the control data in the conventional cages without perches (C). After that, the same hens were trained until they all rested on the perches during the night for 2 weeks using conventional cages with perches available all day (P24), followed by conventional cages with perches from 19.00 to 08.00 hours (P13), and finally housed in conventional cages with perches from 19.00 to 04.00 hours (P9). The interval between each trial was a 10 days to habituate the hens with their new environment. Immediately following this, the behavioral and physiological data were recorded for 2 consecutive days for each trial. Bout lengths were recorded for drinking, feeding, preening and resting, to allow calculation of the overall time spent in these activities during the light and dark period. In addition, during the light period (04.00-19.00 hours), the counts of some comfort behavioral activities such as head scratching, body shaking, head shaking and beak wiping were also measured. The bout lengths and counts of behavioral activities of hens of all cage types were recorded by the continuous focal animal sampling method. 
Statistical analysis

Results were expressed as the mean \pm standard error (SE) in each parameter. Values of behavioral data, HR, BT and LA during the light and dark period between the treatments were tested using a general analysis of a variance model (ANOVA). Further analysis was made by Post hoc tests to determine the source of the detected significance in the ANOVAs. A probability level of $\mathbf{P}<0.05$ was considered significant.

\section{Results}

\section{Behavior}

Figure 1 shows the data obtained on the time of hens spent performing each behavior activities in a whole day except 1 hour from 08.00 to 09.00 hours for routine work (concerning feeding, water supplying, cleaning and egg collection etc.). The time spent of hens drinking and feeding in these four cages were as follows : 22, $262 \mathrm{~min}$ in $\mathrm{C}$; 24, $250 \mathrm{~min}$ in $\mathrm{P} 24$; 17, $263 \mathrm{~min}$ in $\mathrm{P} 13$; and 22, $274 \mathrm{~min}$ in P9 cages ; these differences were not significant. In addition, the time spent preening occupied $142 \mathrm{~min}$ in P13 cages and 137, 121, and 115 min in C, P9, and P24 cages, respectively ; these differences also were not significant. A significant difference was found only for the time spent resting which increased significantly in $\mathrm{P} 24$ cages than in $\mathrm{C}$ and $\mathrm{P} 9$ cages $\left(\mathrm{F}_{3,12}=\right.$ $3.51, \mathrm{P}<0.05)$.

Our observations after lights-off indicated that in cages either with or without perches all hens spent most of the time (19.00 to 04.00 hours) on resting. Furthermore, in the morning observation just after lights-on, all hens in cages with perches were found

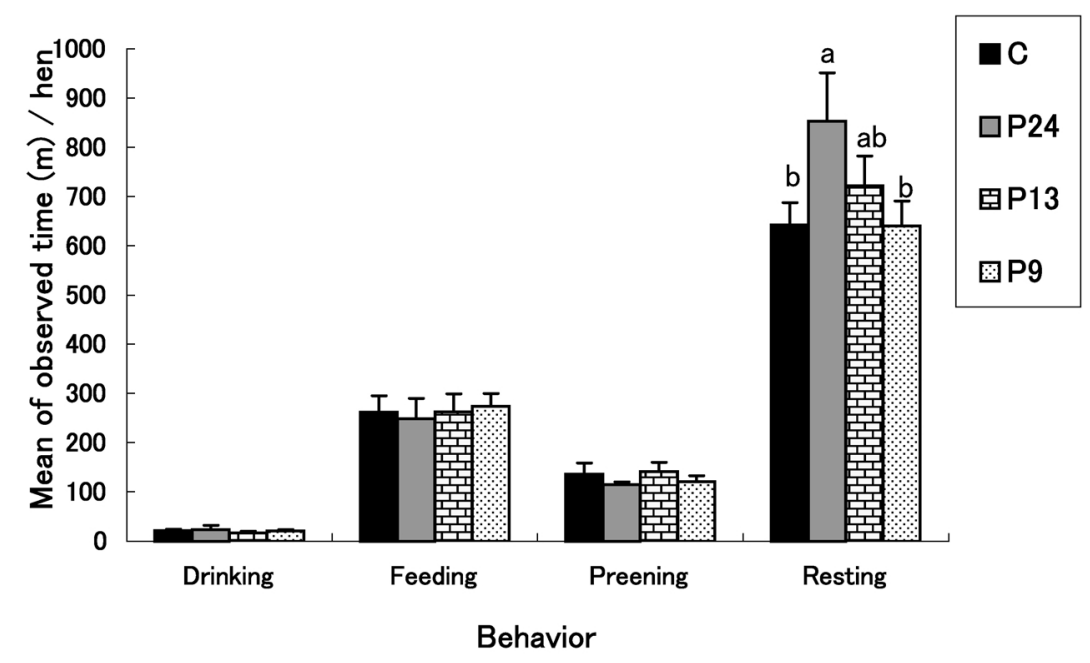

Fig. 1. Mean ( \pm S.E.) time spent on behavioral activities per hen in cages with or without perches during 23 hours $(09.00-08.00 \mathrm{~h})$. $\mathrm{C}$, cages without perches; P24, cages with perches all day; P 13 , cages with perches from 19.00 to 08.00 hours; P9, cages with perches from 19.00 to 04.00 hours. Means with different superscripts are significantly different $(\mathrm{P}<0.05)$. 
perching with almost all of them facing the rear wall. The time spent drinking, feeding, and preening during the light period were generally similar to those mentioned above for a whole day. Only the time spent resting without doing anything else was $303 \mathrm{~min}$ in P24 cages during the light period, which was significantly higher than in C and P9 cages $\left(F_{3,12}=3.57, \mathbf{P}<0.05\right)$ as shown in Fig. 2. Furthermore, the counts of head scratching, body shaking, head shaking, and beak wiping were lower in all the treatments than those in $\mathrm{C}$ cages, but no significant differences were found as shown in Fig. 3.

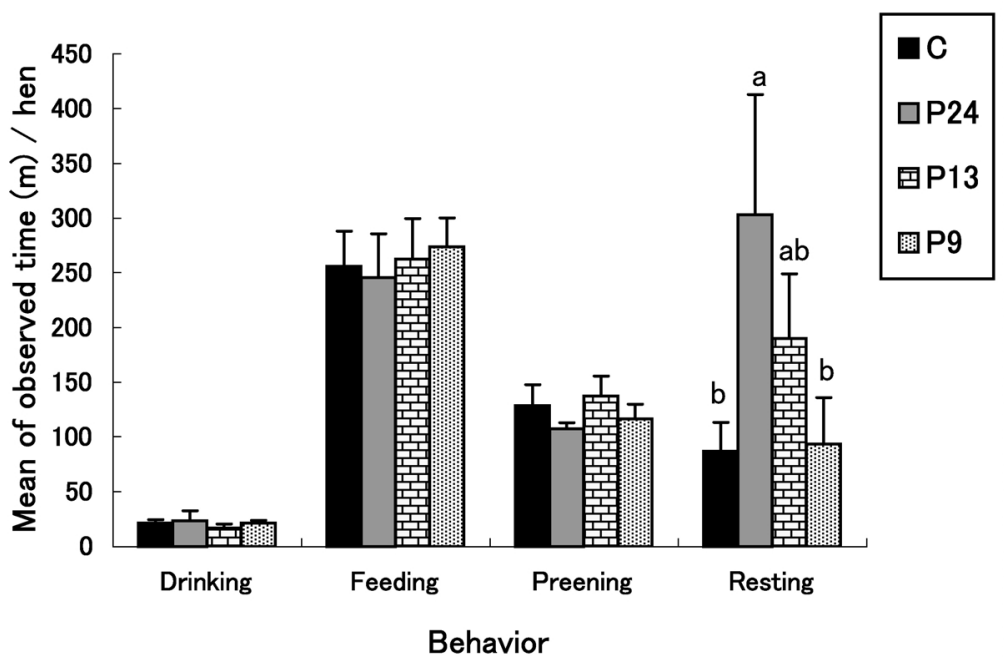

Fig. 2. Mean ( \pm S.E.) time spent on behavioral activities per hen in cages with or without perches during the light period (04.0019.00 h). C, P24, P13 and P9 : see Fig. 1. Means with different superscripts are significantly different $(\mathrm{P}<0.05)$.

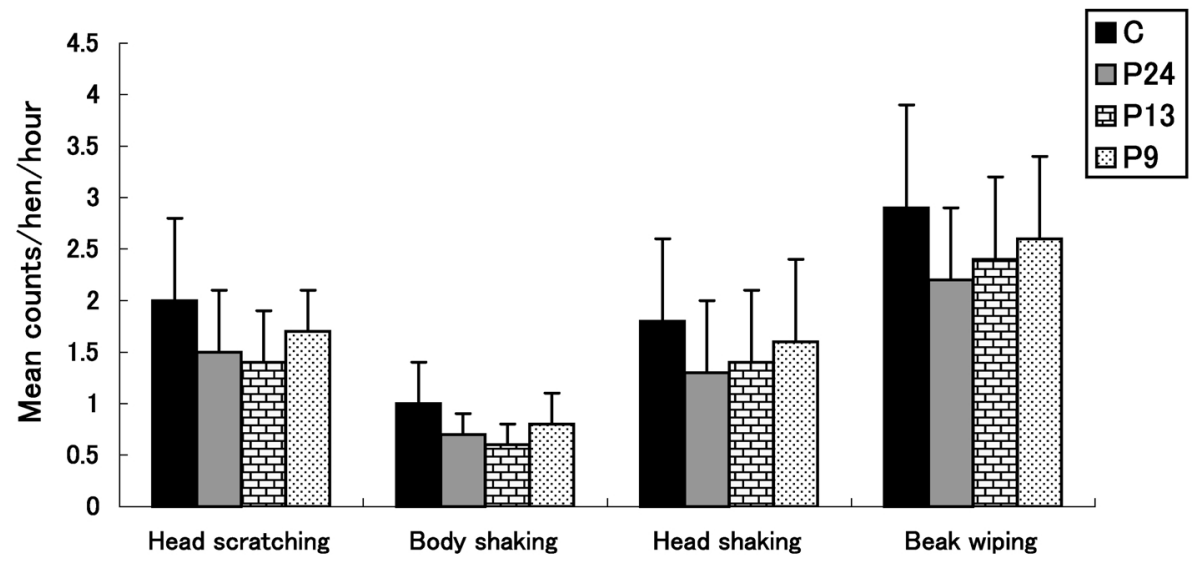

\section{Behavior}

Fig. 3. Mean ( \pm S.E.) counts/hour of different activities per hen in cages with or without perches during the light period (04.0019.00 h). C, P24, P13 and P9 : see Fig. 1. 


\section{Physiological parameters}

Figure 4 shows the HR of the hens in cages with or without perches. During the light period, hens in P24, P13 and P9 cages had a significantly higher HR than in C cages $\left(F_{3,13}=926.72, P<0.01\right)$ as shown in Table 1. However, hens in P24 cages had a significantly lower HR than in $\mathrm{P} 13$ and $\mathrm{P} 9$ cages $(\mathrm{P}<0.01)$, while hens in $\mathrm{P} 9$ cages had a significantly higher HR than in $\mathrm{P} 13$ cages $(\mathrm{P}<0.01)$. On the other hand, during the dark period, hens in P24 cages had a significantly lower HR than in C, P13 and P 9 cages $\left(\mathrm{F}_{3,80}=387.19, \mathrm{P}<0.01\right)$ as shown in Table 2. However, hens in P13 had a significantly lower HR than in $\mathrm{C}$ and $\mathrm{P} 9$ cages $(\mathrm{P}<0.01)$, whereas hens in $\mathrm{P} 9$ cages had
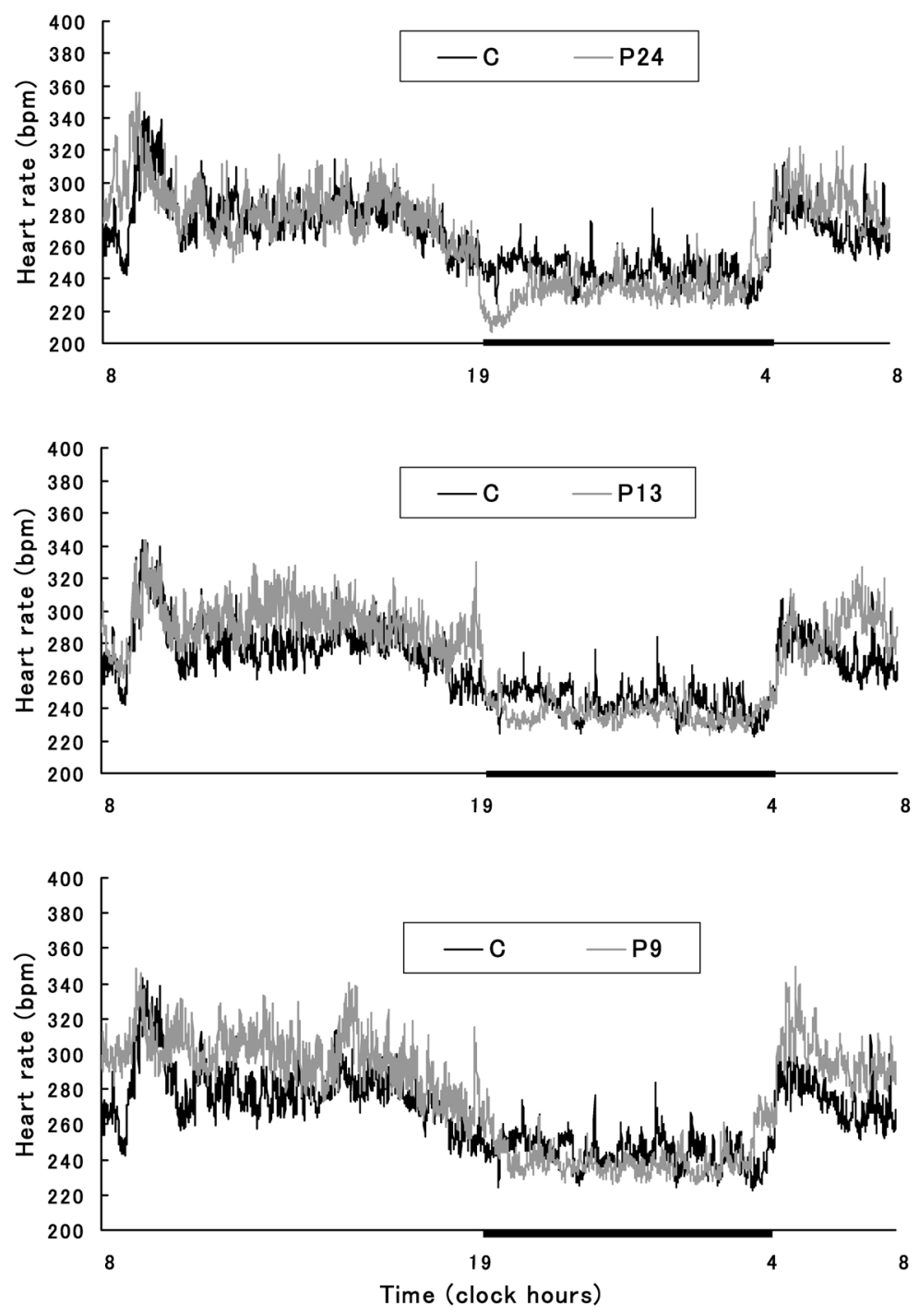

Fig. 4. Mean heart rate changes in cages with or without perches during the light and dark period. C, P24, P13 and P9 : see Fig. 1. Dark bars indicate the dark period. 
a significantly lower HR than in $\mathrm{C}$ cages $(\mathrm{P}<0.01)$.

Figure 5 shows the BT of the hens in cages with or without perches. During the light period, hens in P24 cages had a significantly lower BT than in C, P13 and P9 cages $\left(\mathrm{F}_{3,36}=277.45, \mathrm{P}<0.01\right)$ as shown in Table 1. In addition, hens in $\mathrm{P} 13$ cages had a significantly higher BT than in $\mathrm{C}$ and $\mathrm{P} 9$ cages $(\mathrm{P}<0.01)$. On the other hand, during the dark period, hens in P24, P13 and P9 cages had a significantly lower BT than in C cages $\left(\mathrm{F}_{3,21}=77.945, \mathrm{P}<0.01\right)$ as shown in Table 2 .

Figure 6 shows the LA of the hens in cages with or without perches. During the light period, hens in P24 cages had a significantly higher LA than in C, P13 and P9 cages $\left(F_{3,72}=14.99, P<0.01\right)$, as shown in Table 1 . In contrast, during the dark period, hens in P24 cages had a significantly lower LA than in C, P13 and P9 cages $\left(F_{3,42}=\right.$ 13.83, $\mathrm{P}<0.01$ ) as shown in Table 2. In addition, hens in $\mathrm{P} 13$ cages had a significantly lower LA than in $\mathrm{C}$ and $\mathrm{P} 9$ cages $(\mathrm{P}<0.01)$.

Table 1. Heart rate, body temperature and locomotor activity during light period (04.00-19.00 hours)

\begin{tabular}{cccc}
\hline \hline \multirow{2}{*}{ Treatment } & \multicolumn{3}{c}{ Physiological parameter } \\
\cline { 2 - 4 } & $\begin{array}{c}\text { Heart rate } \\
(\mathrm{bpm})\end{array}$ & $\begin{array}{c}\text { Body temperature } \\
\left({ }^{\circ} \mathrm{C}\right)\end{array}$ & $\begin{array}{c}\text { Locomotor activity } \\
(\text { counts } / 5 \text { min })\end{array}$ \\
\hline C & $227.8 \pm 0.2^{\mathrm{a}}$ & $41.9 \pm 0.0^{\mathrm{a}}$ & $15.1 \pm 1.3^{\mathrm{a}}$ \\
P24 & $283.9 \pm 0.2^{\mathrm{b}}$ & $41.7 \pm 0.0^{\mathrm{b}}$ & $27.0 \pm 2.4^{\mathrm{b}}$ \\
P13 & $290.3 \pm 0.2^{\mathrm{c}}$ & $42.0 \pm 0.0^{\mathrm{c}}$ & $15.1 \pm 1.3^{\mathrm{a}}$ \\
P9 & $297.6 \pm 0.2^{\mathrm{d}}$ & $41.9 \pm 0.0^{\mathrm{a}}$ & $13.4 \pm 1.1^{\mathrm{a}}$ \\
\hline
\end{tabular}

Each value represents mean $( \pm \mathrm{SE}, \mathrm{n}=6)$.

C, P24, P13 and P9 : see Fig. 1.

${ }_{a, b, c, d}$ Means in a column with different superscripts are significantly

different $(\mathrm{P}<0.01)$.

Table 2. Heart rate, body temperature and locomotor activity during dark period (19.00-04.00 hours)

\begin{tabular}{cccc}
\hline \hline \multirow{2}{*}{ Treatment } & \multicolumn{3}{c}{ Physiological parameter } \\
\cline { 2 - 4 } & $\begin{array}{c}\text { Heart rate } \\
(\mathrm{bpm})\end{array}$ & $\begin{array}{c}\text { Body temperature } \\
\left({ }^{\circ} \mathrm{C}\right)\end{array}$ & $\begin{array}{c}\text { Locomotor activity } \\
(\text { counts } / 5 \text { min })\end{array}$ \\
\hline C & $246.9 \pm 0.1^{\mathrm{a}}$ & $41.2 \pm 0.0^{\mathrm{a}}$ & $4.5 \pm 1.1^{\mathrm{a}}$ \\
P24 & $234.3 \pm 0.2^{\mathrm{b}}$ & $41.0 \pm 0.0^{\mathrm{b}}$ & $0.5 \pm 0.1^{\mathrm{b}}$ \\
P13 & $239.5 \pm 0.2^{\mathrm{c}}$ & $41.1 \pm 0.0^{\mathrm{c}}$ & $2.8 \pm 0.8^{\mathrm{c}}$ \\
P9 & $245.7 \pm 0.3^{\mathrm{d}}$ & $41.1 \pm 0.0^{\mathrm{c}}$ & $4.2 \pm 0.2^{\mathrm{a}}$ \\
\hline
\end{tabular}

Each value represents mean $( \pm \mathrm{SE}, \mathrm{n}=6)$.

C, P24, P13 and P9 : see Fig. 1.

a,b,c,d Means in a column with different superscripts are significantly

different $(\mathrm{P}<0.01)$. 


\section{Discussion}

\section{Behavior}

Duncan et al. (1992) have pointed out that the physical condition of hens was affected by perch management, including perch cross-section and perch position. They found that the instability inherent in circular perches was associated with foot damage, and that this was at its worst in cages with circular, front perches during the day. Moreover, circular perches may not provide sufficient stability for birds in situations requiring muscular relaxation, e.g., during sleep, especially at night. For hens in the
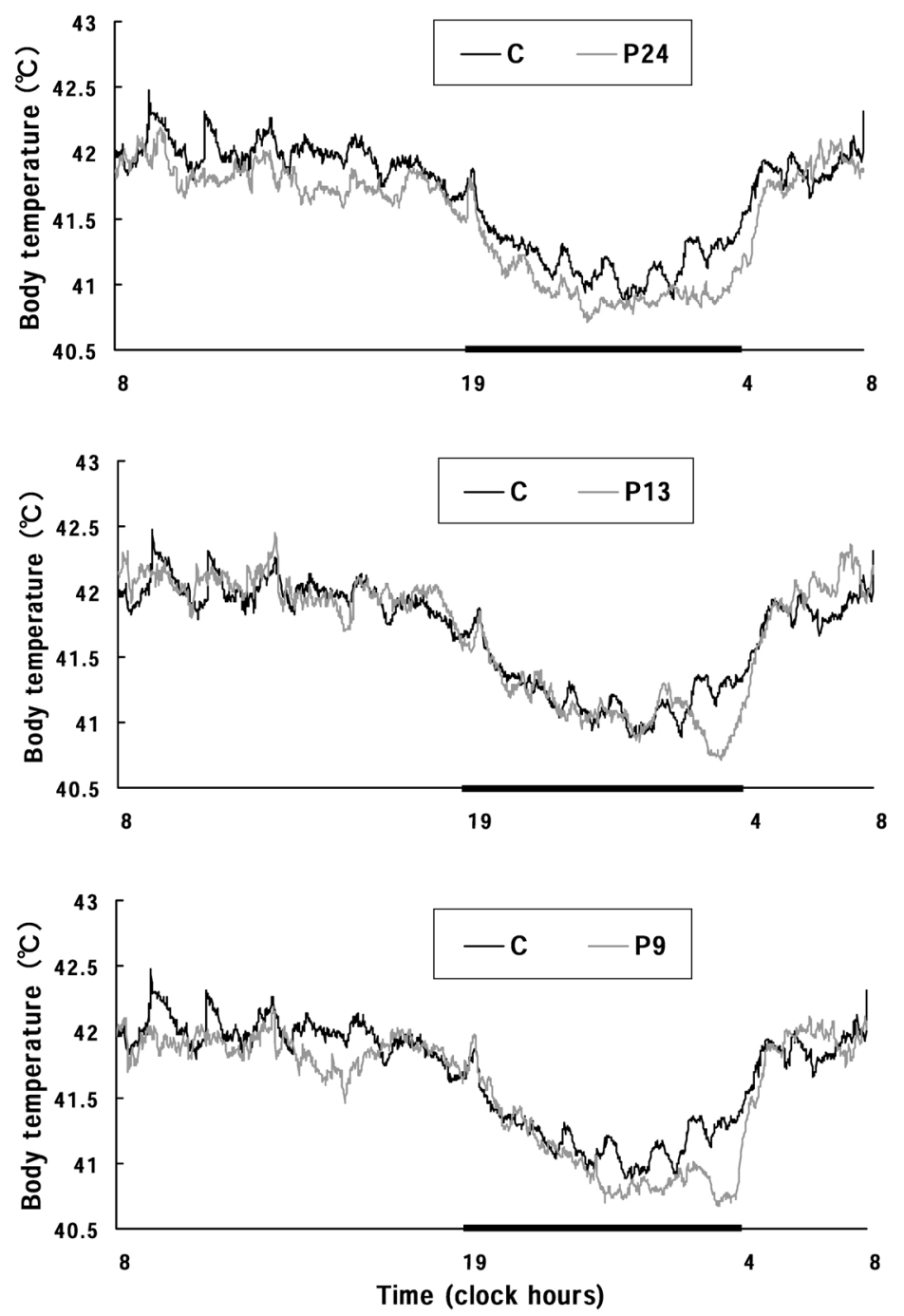

Fig. 5. Mean body temperature changes in cages with or without perches during the light and dark period. C, P24, P13 and P9: see Fig. 1. Dark bars indicate the dark period. 
present study, we used rectangular, rear perches which reduced foot damage and were more comfortable than the cages with circular, front perches. Furthermore, it has been found that perch material does not affect perching behavior, providing there is no variation in surface temperature (Lambe and Scott, 1998). In the present study, we used soft wood which has advantageous, as it holds heat well, is relative inexpensive (as compared to PVC or plastic), and is malleable (allowing birds to secure claws in the material when perched).

Our finding indicates that the hens did frequent use of the perches for resting and for preening during the light period and for perching during the dark period, in preference to sloping wire floor, and this fact was in agreement with a previous report
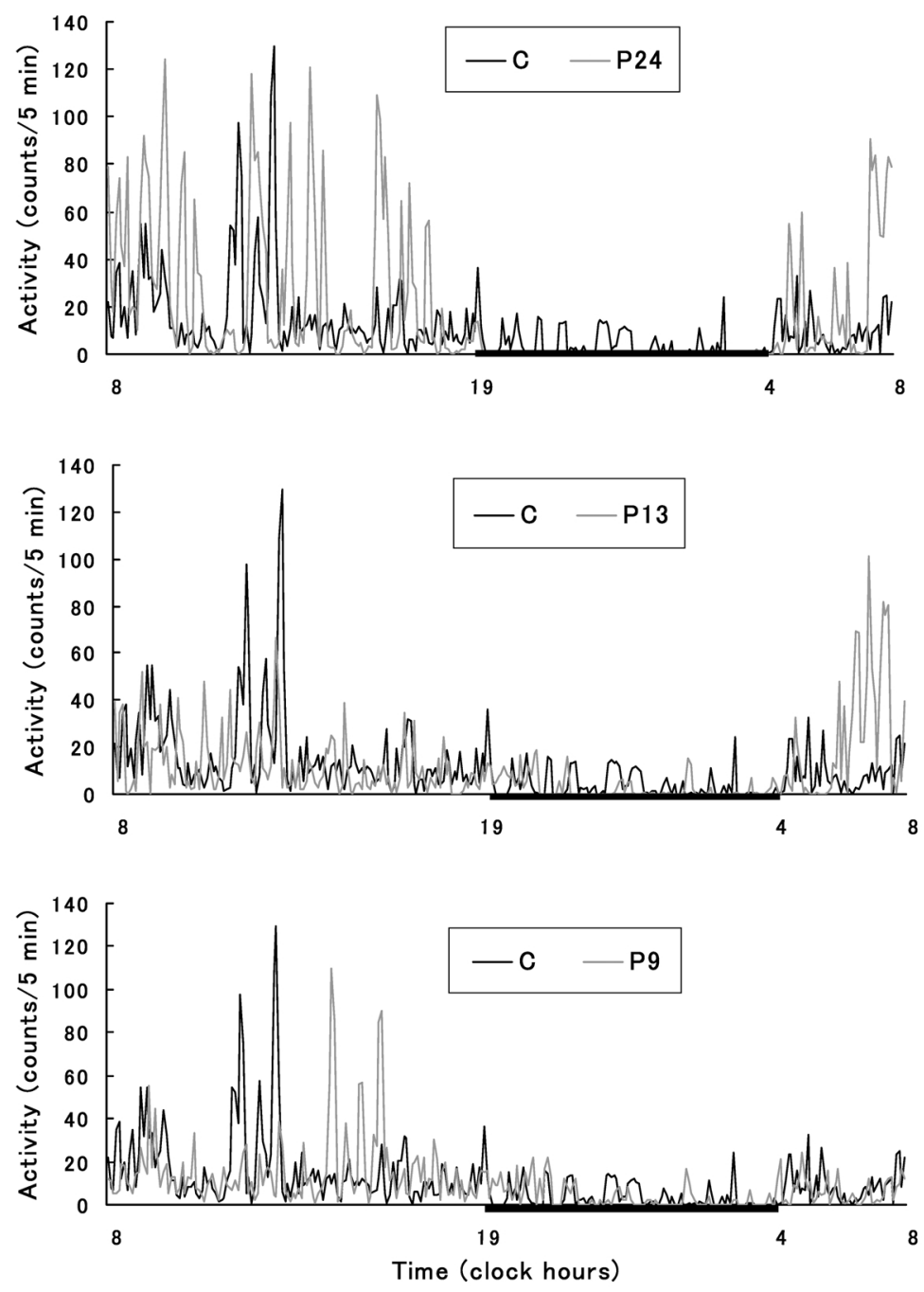

Fig. 6. Mean locomotor activity changes in cages with or without perches during the light and dark period. C, P24, P13 and P9 : see Fig. 1. Dark bars indicate the dark period. 
(Braastad, 1990). Therefore, hens in P24 cages spent significantly more time resting than in $\mathrm{C}$ cages with no perches and $\mathrm{P} 9$ cages with perches only during the dark period. Moreover, preening activity was lower in P24 cages than in the others, possibly due to giving the P24 hens more time to satisfy their resting needs. On the other hand, there were no further significant differences in other behavioral activities among all treatment, suggesting that the perches did not necessarily prevent the performance of comfortable behavior activities among hens, but provided them with rest and welfare.

\section{Physiological parameters}

From the light period data (04.00-19.00 hours), we found that the P24 cages had a significantly higher $\mathrm{HR}$ than the $\mathrm{C}$ cages resulting from the highest LA because the hens were much more likely to jump on the perches during most of the daytime, and hence the provision of perches for laying hens may have been satisfied a natural behavioral activity. Nevertheless, the BT level in P24 cages was the lowest among all the treatment, which might have contributed to less time spent in feeding and drinking and more time spent in resting. From these results, it is a reasonable assumption that P24 cages allow hens to engage in various activities in a balanced manner, consequently providing them with a better environment.

During the dark period, we observed that all hens usually perched at night. Therefore, the LA in cages with perches was lower than in cages without them leading to lowering in HR and BT in these cages. From the comparison, we found that the hens in P24 cages had the significantly lowest HR as a result of having the lowest LA among all treatment. Furthermore, BT in P24 cages showed the lowest rate, probably due to more relaxed sitting position on a perch which lead to feeling of comfortable sleep and consequently reduced heat loss via comb and wattles during the night (Braastad, 1990).

Generally, there are potential welfare problems in cages without perches due to increased aggression, reduced bone strength, impaired foot condition, and higher feather loss (Baxter, 1994). Hence, the provision of perches for laying hens satisfies a natural behavioral activity and may therefore be practical in commercial production without increasing the number of cracked eggs (see Introduction). For the amelioration of this disadvantage of conventional cages, provision of perches should be combined with other modification such as nest box (Appleby, 1993).

In conclusion, from behavioral and physiological point of view in the present study, it was suggested that the cages with perches might improve the hens' welfare than those without perches. Furthermore, our data verify that the use of perches all day as environmental enrichment might provide hens with more comfortable environment than all the other treatments, and is one method in which welfare in barren cages may be improved.

\section{Acknowledgment}

This work was supported by Japan Society for the Promotion of Science (JSPS).

\section{References}

Appleby MC. Should cages for laying hens be banned or modified? Animal Welfare, $2: 67-80$. 
1993.

Appleby MC. Perch length in cages for medium hybrid laying hens. British Poultry Science, 36 : 23-31. 1995.

Baxter MR. The welfare problems of laying hens in battery cages. Veterinary Record, $134: 614^{-}$ 619. 1994.

Braastad BO. Effects on behaviour and plumage of a key-stimuli floor and a perch in triple cages for laying hens. Applied Animal Behaviour Science, 27 : 127-139. 1990.

Dorminey RW and Arscott GH. Effects of bird density, nutrient density and perches on the performance of caged White Leghorn layers. Poultry Science, 50 : 619-626. 1971.

Duncan ET, Appleby MC and Hughes BO. Effect of perches in laying cages on welfare and production of hens. British Poultry Science, 33 : 25-35. 1992.

Hughes BO and Elson HA. The use of perches by broilers in floor pens. British Poultry Science, $18: 715-722.1977$.

Hughes BO and Appleby MC. Increase in bone strength of spent laying hens housed in modified cages with perches. Veterinary Record, 124 : 483-484. 1989.

Korte SM, Ruesink EW and Blokhuis HJ. Heart rate variability during manual restraint in chicks from high- and low- feather pecking laying hens. Physiology and Behavior, 65 : 649-652. 1999.

Lambe NR and Scott GB. Perching preferences for different perch design among laying hens. Animal Welfare, 7 : 203-216. 1998.

Robertson ES, Appleby MC, Hogarth GS and Hughes BO. Modified cages for laying hens : a pilot trial. Research and Development in Agriculture, 6 : 107-114. 1989.

Ruzler PL and Quisenberry JH. The effect of perches on various performance factors of caged layers. Poultry Science, 49 : 1433 (Abstract). 1970.

Tanaka T, Ozaki T and Watanabe T. Effects of perches on behavior and performance of caged hens. Japanese Poultry Science, 30 : 183-189. 1993.

Tauson R. Effects of a perch in conventional cages for laying hens. Acta Agriculture Scandinavia, 34 : 193-209. 1984.

Tauson R. Health and production in improved cage designs. Poultry Science, 77 : 1820-1827. 1998.

Webster AB and Hurnik JF. Behavior, production, and well-being of the laying hen. 1. Effects of movable roosts, relationship of cage mates, and genetic stock. Poultry Science, 69 : 21182127. 1990.

Wilson S, Hughes BO, Appleby MC and Smith SF. Effects of perches on trabecular bone volume in laying hens. Research in Veterinary Science, 54 : 207-211.1993. 